\title{
A License Plate Reader using AVR Microcontroller
}

\author{
Trishala Chougule \\ M.E. E\&TC (VLSI and Embedded) \\ Dr. D. Y. School of Engineering \\ Pune, India
}

\author{
Saniya Ansari \\ M.E. Co-Ordinator E\&TC (VLSI and Embedded) \\ Dr. D. Y. School of Engineering, \\ Pune, India
}

\begin{abstract}
License Plate Recognizer is an efficient and effective system to identify the vehicles. In this paper we represent the simple and effective technique to identify the Indian license plate. This Proposed system consist tree steps, first is extraction of license plate from a captured image by camera. Second step is segmentation of the character from number plate and extract. And the last step is recognizing the characters and display it informs of text. So in this paper for first step used technique is morphological operation, for second step we used histogram to extract the numbers. For recognition we used the template matching by cross correlation between extracted character and database. At last to display recognized number plate at long distance on the LCD display AVR microcontroller is used.
\end{abstract}

\section{Keywords}

License Plate Recognizer, Sobel Filter, Segmentation

\section{INTRODUCTION}

As the transportation play a vital role in day to day life. Because of growing in population numbers of vehicles are increased. So to control on traffic conjunctions and to follow the traffic rules the VLPR system play an important role. The number plate is a unique identity of vehicle. By using this identity we can maintain the information related to car like name of car owner, insurance of car, driving license duration etc. which is useful for traffic police.

There are lots of techniques and software available for license plate recognition. Software like Open CV, Matlab, are mainly used for image processing which helps to extract the license plat from an Captured images. In this paper we used Matlab software for image processing. AVR microcontroller is used to display the license number and name of car owner..

\section{LTERATURE SURVEY}

A License Plate-Recognition Algorithm for Intelligent Transportation System Applications in this method for plate extraction[1] used is Sliding Concentric Window, its result is $96 \%$, SCW is used for character segmentation its result is $89 \%$, And for character recognition in this paper ANN with two layer PNN. An Efficeint Method of Vehicle License Plate Recognition Based on Sliding Concentric Windows and Artificial Neural Network[2] used is Sliding Concentric Window. And for character segmentation Edge detection technique is used in paper. And for character recognition in this paper ANN. A New License Plate Recognition System Based on Probabilistic Neural Networks [3] in this paper for extraction the number plate Bottom-Hat filtering, Otsu's

Thresholding method is used, Column sum vector (CSV) charts are used for character segmentation. Finally character recognized using PNN-Probabilistic Neural Network. Artificial neural networks based vehicle license plate recognition[4] Canny edge detector and Gaussian Filter for extraction the number plate and for segmentation blob (Binary Large Object) coloring algorithm finally for recognition ANN.
Multi-features-based License Plate Detection in Nighttime Environment [5] variable scanning window for nuber plate extraction, Horizontal And Vertical Projection for character segmentation mthods are used. A Novel Approach for Vehicle License Plate Localization and Recognition[6] in this paper Canny edge detedtor and Gaussian Filter, Traditional method and Horizontal And Vertical Projection are the method for extraction, segmentation and character recognition used respectively. Research and Implementation of a License Plate Recognition Algorithm Based on Hierarchical Classification [7] In this paper wavelet packet decomposition and K-L transform, Wavelet Packet Transform and LIB SVM are the methods used for extraction segmentation and recognition respectively.

Saudi Arabian license plate recognition system[8] used method for segmentation vertical edge matching, Normalization and Template matching for segmentation of plate, segmentation of character and recognition respectively. Automatic Vehicle Identification by Plate Recognition[9], edge detection algorithms and smearing algorithms applied for plate segmentation, smearing algorithms, filtering and some morphological algorithms for segmentation of character And finally Template matching is for character recognition. Automatic new license plate recognition in Egypt [12]. the edge detection algorithms and smearing algorithms is used for extraction and its result is $97.60 \%$ smearing algorithms, filtering and some morphological algorithms is used for character segmentation its result is $98.80 \%$. finally for recognition they used Template matching.

\section{PROPOSED METHOD}

The proposed frame work is shown in fig. 1 Proposed method contain four step 1) Number plate extraction 2) Character segmentation 3) Character recognition 4) AVR hardware for display

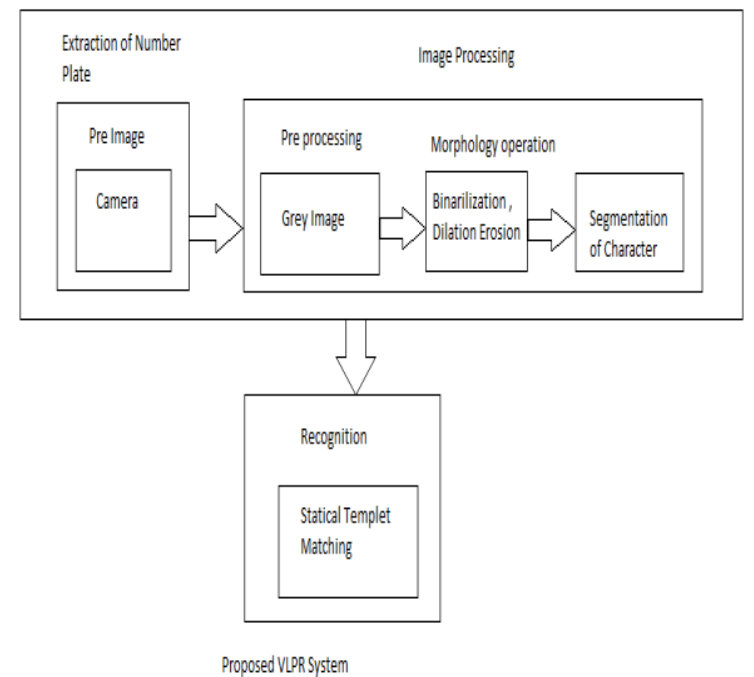




\subsection{Extraction of Number Plate}

This is most important step in VLPR system

a) Preprocessing - As various types of cameras with different resolution are available in market so first step in this is resize the captured image. In our system captured image size is 3264 $\mathrm{x} 2448$ fig. 1 which is too big for processing so resized it into 1315 x 489 Fig2.

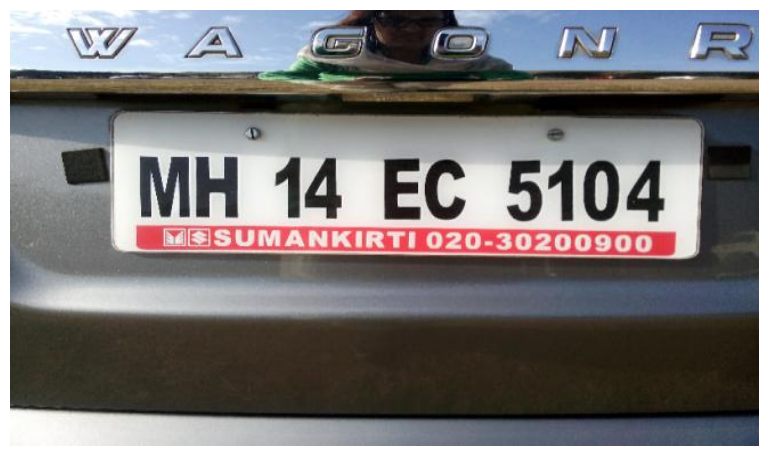

Fig. 1 Original Image

Then converted coloured image into gray image and to remove noise median filter is used as shown in fig. 3

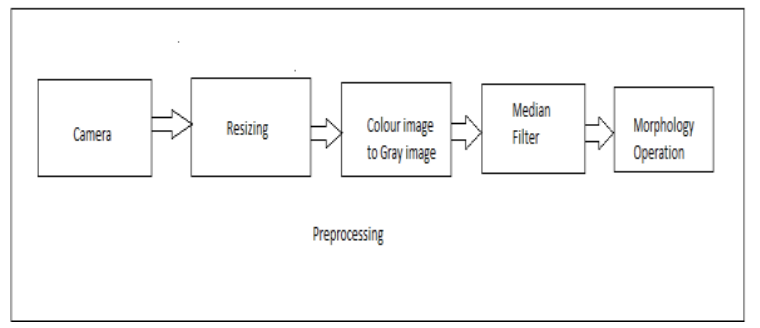

Fig. 2 Preprocessing Steps

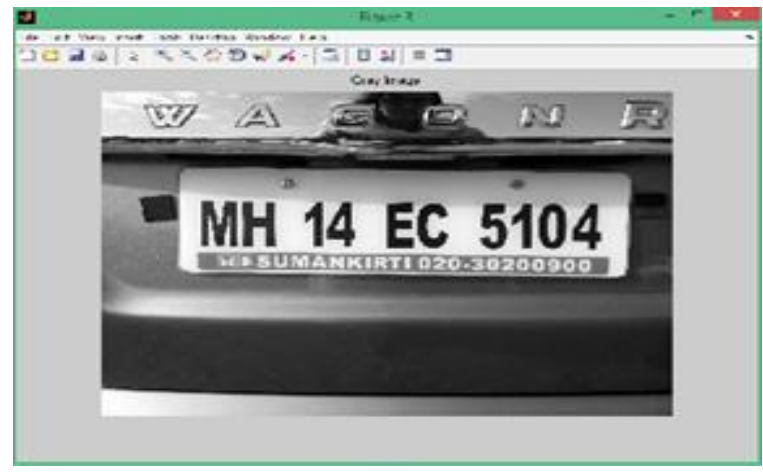

Fig. 3 Gray Image

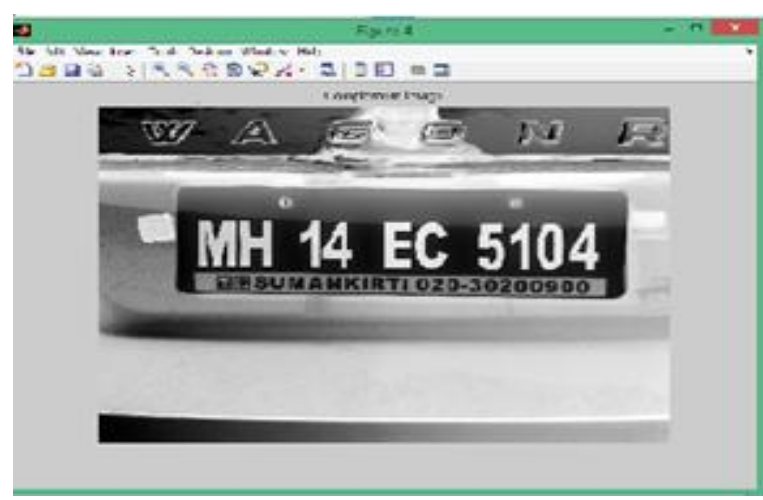

Fig. 4 Complement images
In image processing first step is convert RBG image into gray image, it improve the speed of processing and easy to extract area of interest. As there are lot of filters in MATLAB for edge detection like Sobel, canny, Prewitt. To find good method for extraction of number plate following filters are applied

a) Sobel Filter - Sobel filter is also known as sobel operator. It is used for edge detection in an image. Sobe operator is $3 \times 3$ matrices. One is Gx which convolves in horizontal direction from right to left. And other Gy which convolves in vertical direction top to bottom.

$$
\begin{aligned}
& \mathrm{Gx}=\left[\begin{array}{ccc}
-1 & 0 & +1 \\
-2 & 0 & +2 \\
-1 & 0 & +1
\end{array}\right] \\
& \mathrm{Gy}=\left[\begin{array}{ccc}
-1 & -2 & -1 \\
0 & 0 & 0 \\
+1 & +2 & +1
\end{array}\right]
\end{aligned}
$$

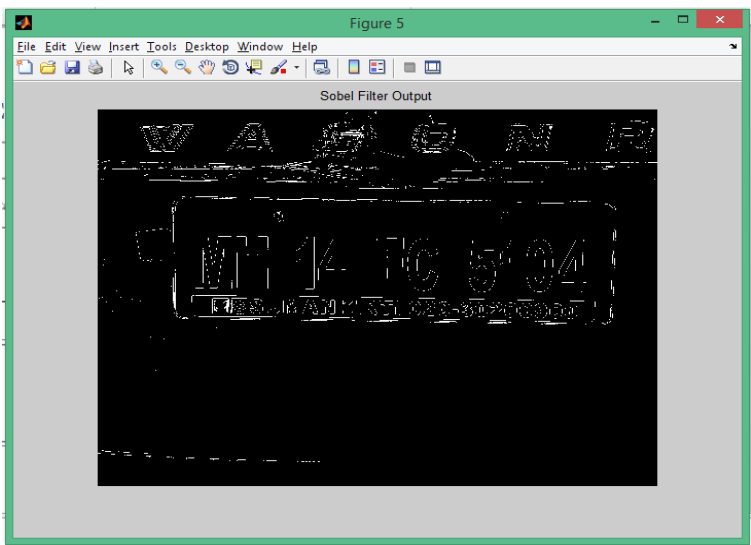

Fig. 5 Sobel filter output

b) Canny Filter -In canny filter first Apply Gaussian filter to smooth the image in order to remove the noise[15]. Then to find the intensity gradients of the image we apply non-maximum suppression to get rid of spurious response to edge detection. In this require two thresholds to determine potential edges Track edge by hysteresis: Finalize the detection of edges by suppressing all the other edges that are weak and not connected to strong edges.

$$
\mathbf{B}=\frac{1}{159}\left[\begin{array}{ccccc}
2 & 4 & 5 & 4 & 2 \\
4 & 9 & 12 & 9 & 4 \\
5 & 12 & 15 & 12 & 5 \\
4 & 9 & 12 & 9 & 4 \\
2 & 4 & 5 & 4 & 2
\end{array}\right] * \mathbf{A}
$$

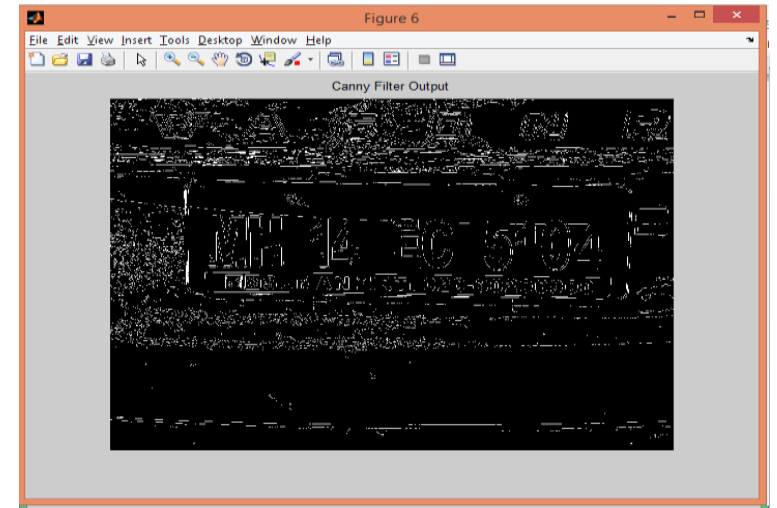

Fig 6. Canny Filter output 
c) Morphological operation - This operation done by using two functions imdilate and imerode.[13] Imdilate function increase the area of white pixel and imerode remove the pixel or convert the pixel white into black at the each edges. After subtraction of these images we got sharp and continuous edges.

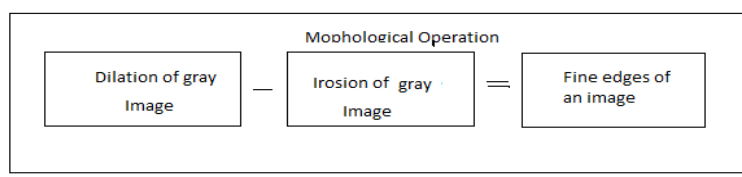

Fig 7 Morphology Operation

In image processing first step is convert RBG image into gray image, it improve the speed of processing and easy to extract area of interest.[16] As there are lot of filters in MATLAB for edge detection like Sobel, canny, Prewitt. To find good method for extraction of number plate following filters are applied

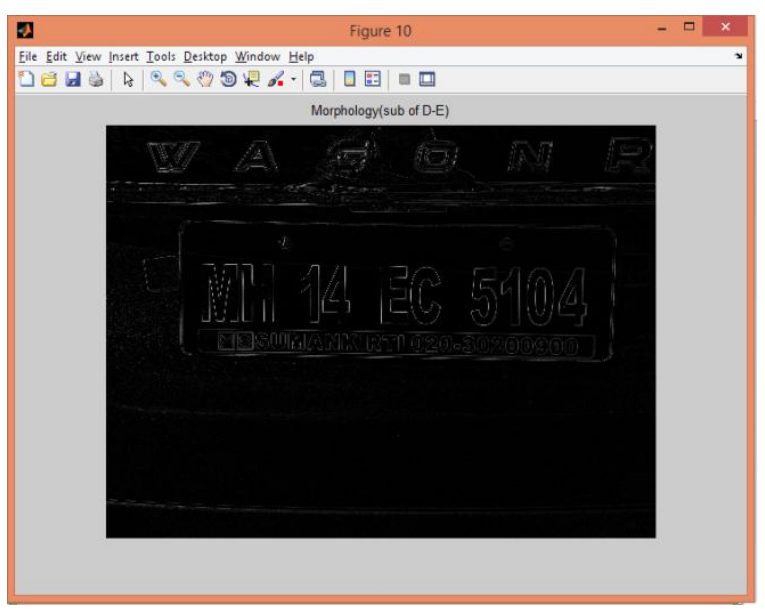

Fig. 8 Morphology Output

\subsection{Character Segmentation}

Segmentation is most important element to separate the characters. At this step other objects like screw on plate other character, and small laminated area may be taken as character. So we chose a correct area of character by using matrix. [11]After morphology operation fill the character s by white. Vertical projection algorithm is used to select the area. In this we check the character region by comparing with big area \pm 20 pixels. Then check is there black space between two white blob.If there is space then crop the area

If there is no space then check size of area of white pixels if it is less than 100 pixel, then convert the area into black. If it is more than 100 pixels consider it as character, and Crop the area.

\subsection{Character Recognition}

After segmentation of characters and numbers it fitted into fixed block size $24 \times 42$. These blocks will matched with the strored data base as shown in fig. 9. [12]The statistical correlation type is used to matching the characters and numbers. As there are two signals one is of extracted character and other is from database and correlate them, this is known as cross correlation. The following equation shown cross correlation between two discrete signals.

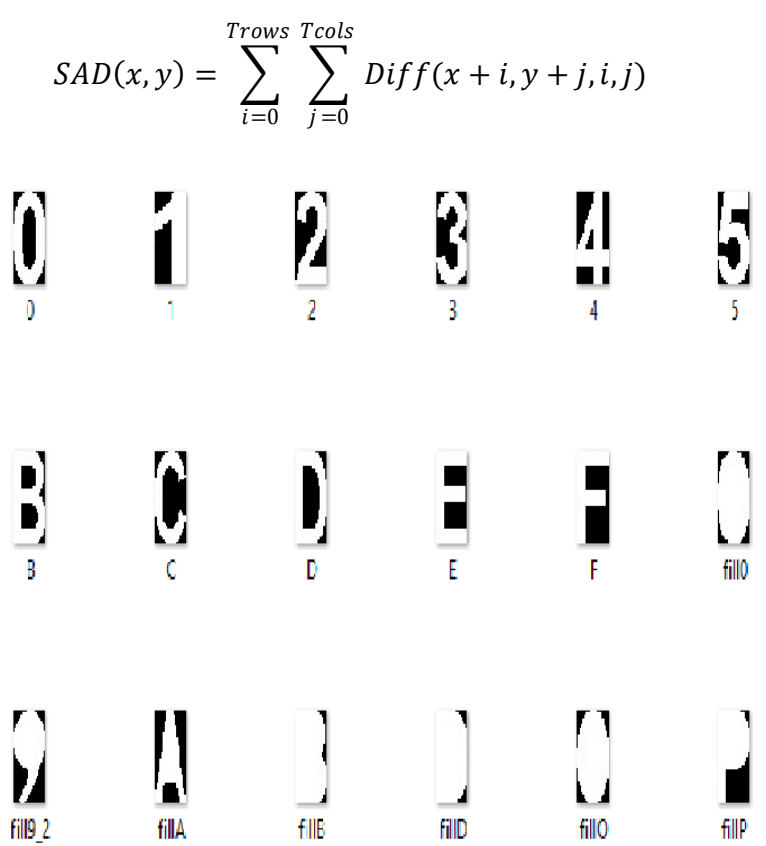

Fig.9. Database for template matching

\section{GUI}

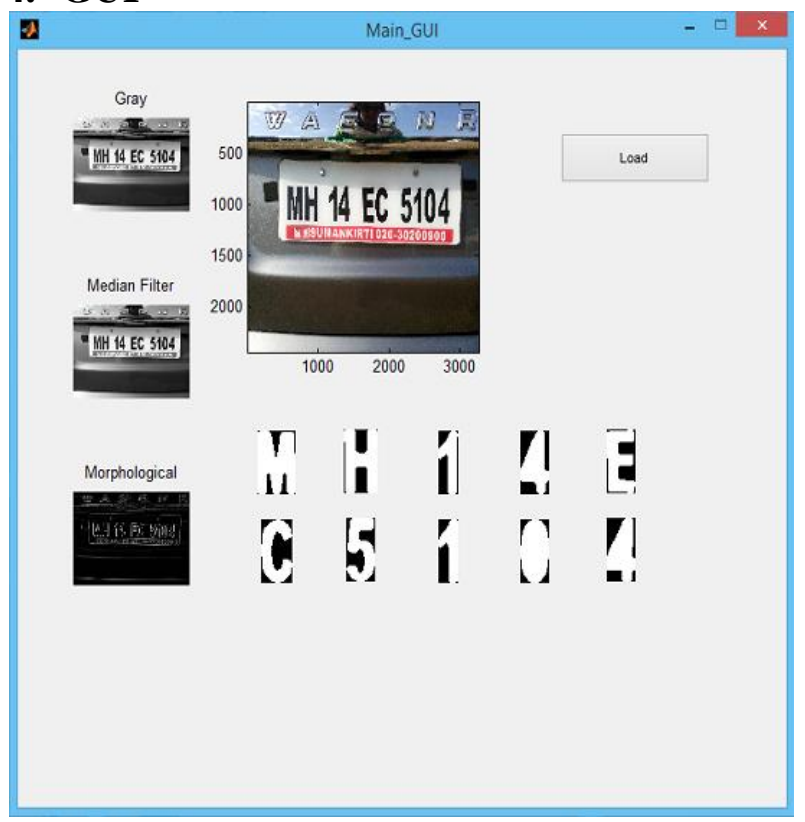

Fig 10 GUI

The graphical user interface is shown in fig 10. In this We show original image captured in camera the gray image, filter output, morphology operation output, Segmentated characters and Load button.

\section{HADWARE}

We used hardware to show the number plate and name of car owner. AVR microcontroller is used for serial communication between computer and display. As matlab gives the floating 32 bit in serial communication. So convert the 32 bit into integer 8 bits. For serial communication the baud rate is 9600 bps. 


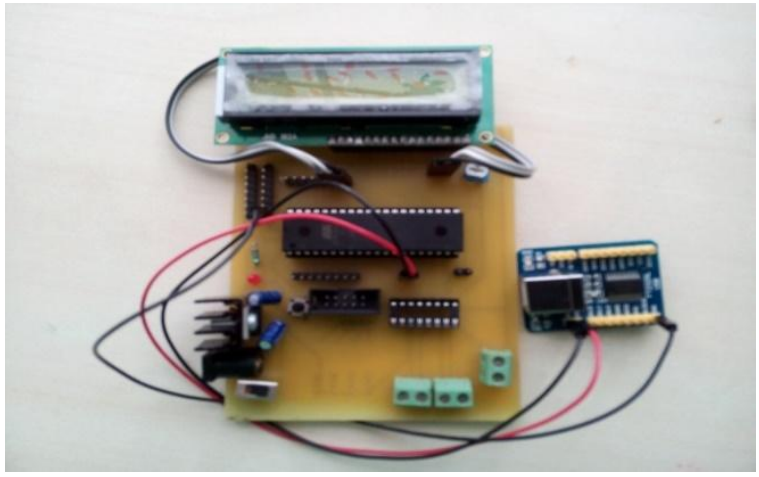

Fig 11 Hardwarwe AVR with LCD

\section{RESULT}

Table 1. Image preprocessing results

\begin{tabular}{|l|l|l|l|l|}
\hline Parameters & $\begin{array}{l}\text { Sobel } \\
\text { Filter }\end{array}$ & $\begin{array}{l}\text { Canny } \\
\text { Filter }\end{array}$ & $\begin{array}{l}\text { Prewitt } \\
\text { Filter }\end{array}$ & $\begin{array}{l}\text { Morphology } \\
\text { Filter }\end{array}$ \\
\hline MSE & 2.7613 & 2.7595 & 2.7603 & 2.7595 \\
\hline PSNR & 13.7196 & 13.7224 & 13.7211 & 13.7224 \\
\hline
\end{tabular}

From the table it is seen that there is no major difference in MSE and PSNR. So from the observation fig 5. And fig 8 objectively the number plate is more clear in morphology filter output. So Morphology filter is better than other filter for this application.

Table 2. Results of proposed System

\begin{tabular}{|l|l|l|l|l|}
\hline $\begin{array}{l}\text { Sr. } \\
\text { No. }\end{array}$ & Parameter & $\begin{array}{l}\text { Number } \\
\text { Plate } \\
\text { extraction }\end{array}$ & $\begin{array}{l}\text { Character } \\
\text { Segmentation }\end{array}$ & $\begin{array}{l}\text { Character } \\
\text { recognition }\end{array}$ \\
\hline 1 & $\begin{array}{l}\text { Number } \\
\text { of images }\end{array}$ & 100 & 100 & 100 \\
\hline 2 & Result & 90 & 92 & 89 \\
\hline
\end{tabular}

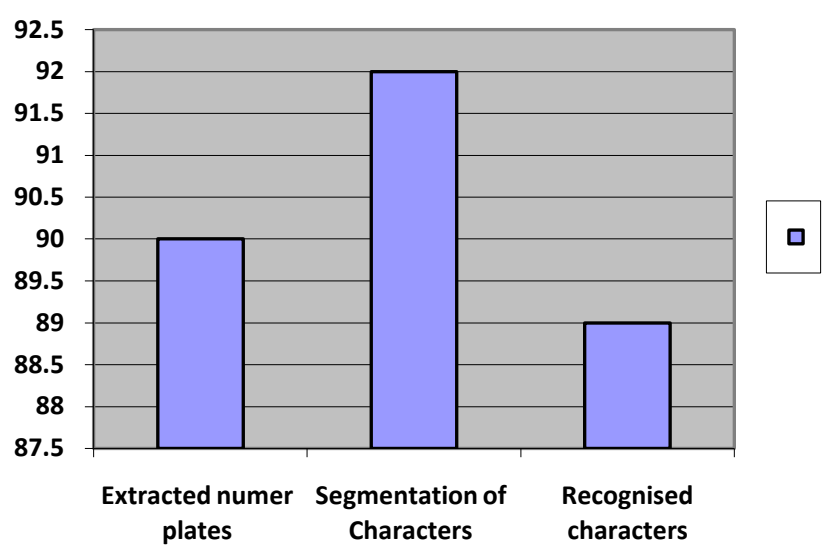

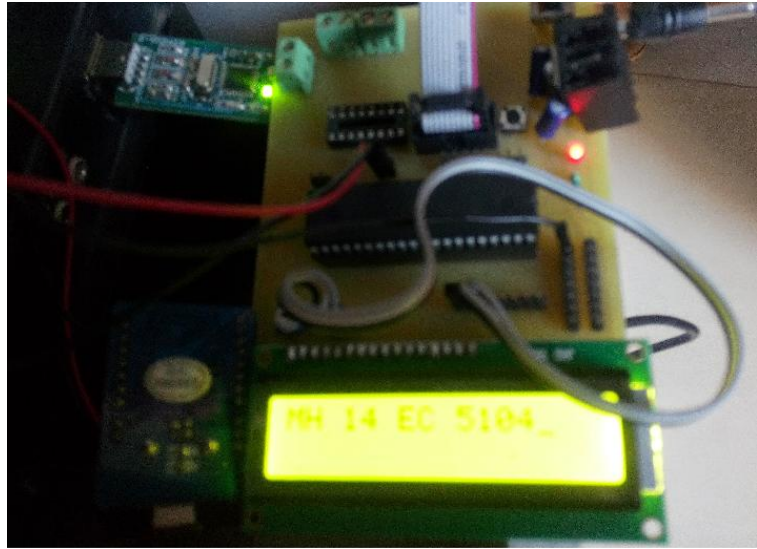

\section{CONCLUSION}

This System is desinged for the Indian plates. We tested this system over 100 images in different environments. VLPR system extract number plate exactly 90 . At character segmentation stage we got result $92 \%$. And recognition stage it recognized the character $89 \%$. at last output of hardware is $100 \%$. As in India mostly not following the rule of license plate. And most of vehicles are having different different fonts, shaps and syles. So it creat difficultly in recognition stage. The future scop of this system can use for real time which is used for security porpose in big industries, IT park, School and collages.

\section{REFERENCES}

[1] 'A License Plate-Recognition Algorithm for Intelligent Transportation System Applications,' Christos Nikolaos E. Anagnostopoulos, Ioannis E. ISSN :1524-9050, Sept. 2006

[2] 'An Efficeint Method of Vehicle License Plate Recognition Based on Sliding Concentric Windows and Artificial Neural Network.' Kaushik Deb, Ibrahim Kahn, Anik Saha, and Kang-Hyun Jo, Volume 4, 2012, sciencedirect

[3] A New License Plate Recognition System Based on Probabilistic Neural Networks,' Fikriye Öztürka, Figen Özena CevikbHaliç University, Electrical and Electronics Engineering Department, Şişli, Istanbul, Turkey Procedia Technology01/2012;1:124-128.

[4] 'Artificial neural networks based vehicle license plate recognition,' H.Erdinc Kocera, K.Kursat Procedia Computer Science 3 (2011) 1033-1037

[5] 'Multi-features-based License Plate Detection in Nighttime Environment,' Jia Li, Journal of Software, Vol 9, No 9 (2014), 2353-2360, Sep 2014

[6] 'A Novel Approach for Vehicle License Plate Localization and Recognition' Muhammad H Dashtban Zahra Dashtban Hassan Bevrani, International Journal of Computer Applications (0975 - 8887) Volume 26No.11, July 2011

[7] Gao, H. , Sun, W. , Liu, X. and Han, M. (2014) Research and Implementation of a License Plate Recognition Algorithm Based on Hierarchical Classification. Journal of Computer and Communications, 2, 25-30. doi:10.4236/jcc.2014.22005

[8] 'Novel Approach for Localization of Indian Car Number Plate Recognition System using Support Vector Machine,' Ms. Sonali Sonavane Prof. Alka Khade Prof. 
V. B. Gaikwad, International Journal of Scientific \& Engineering Research, Volume 4, Issue 8, August-2013 1258 ISSN 2229-5518

[9] 'Saudi arebian licence plate recognition system,' Muhammad Sarfraz, Mohammed Jameel Ahmed, and Syed A. Ghazi, 0-7695-1985-7, July 2003

[10] 'Automatic Vehicle Identification by Plate Recognition,' Serkan Ozbay, and Ergun Ercelebi, International Journal of Electrical, Computer, Electronics and Communication Engineering Vol:1 No:9, 2007

[11] 'A Vehicle License Plate Recognition System Based on Analysis of Maximally Stable Extremal Regions,' Bo Li, Bin Tian, Qingming Yao, Kunfeng Wang., 978-1-46730390-3/12/\$31.00 @2012 IEEE399

[12] 'Automatic new license plate recognition in Egypt', M. A. Masooud, M. Sabee, M. Gergais. R. Bakhit.

[13] D. Zheng,Y. Zhao and J.Wang, "An efficient method of license plate location," Pattern Recognition Letters, vol.26, pp. 2431-2438, 2005.

[14] Artificial neural networks based vehicle license plate recognition H.Erdinc Kocera, K.Kursat Cevikb aSelcuk Uni. Technical Education Faculty, Konya 42250, Turkey
bNigde Uni. Bor Vocational High School, Nigde 51700, Turkey

[15] Automated new license plate recognition in Egypt, M.A. Massoud *, M. Sabee, M. Gergais, R. Bakhit, Faculty of Engineering, El-Minia University, Egypt Received 2 August 2011; revised 20 January 2013; accepted 21 February 2013,Available online 26 March 2013

[16] An Efficient Method of Vehicle License Plate Recognition Based on Sliding Concentric Windows and Artificial Neural Network Kaushik Deba, Md. Ibrahim Khana, Anik Sahaa, and Kang-Hyun Job aFaculty of CSE, Chittagong University of Engineering and Technology (CUET), Chittagong-4349, Bangladesh Faculty of Electrical Engineeering and Information Systems,University of Ulsan,Ulsan-680749, South Korea

[17] ]Muhammad Sarfraz, Mohammed Jameel Ahmed, and Syed A. Ghazi ,"Saudi arebian licence plate recognition system", International Conference on Geometric Modeling and Graphics (GMAG'03), 2003.

[18] Serkan Ozbay, and Ergun Ercelebi," Automatic Vehicle Identification by Plate Recognition", Processing of world academy of science engineering and technology vol9, ISSN 1307-6884, november 2005. 